\title{
Trends in physical activity status in Catalonia, Spain (1992-2003)
}

\author{
Blanca Román-Viñas ${ }^{1}$, Lluís Serra-Majem ${ }^{1,2,3, *}$, Lourdes Ribas-Barba ${ }^{1}$, Eulàlia \\ Roure-Cuspinera ${ }^{3}$, Carmen Cabezas ${ }^{3}$, Carles Vallbona ${ }^{3,4}$ and Antoni Plasencia ${ }^{3}$ \\ 'Community Nutrition Research Centre, University of Barcelona Science Park, Baldiri Reixac 4, Torre D 4A1, \\ 08028 Barcelona, Spain: ${ }^{2}$ Department of Clinical Sciences, University of Las Palmas de Gran Canaria, Las \\ Palmas de Gran Canaria, Spain: ${ }^{3}$ Division of Public Health, Department of Health, Generalitat of Catalonia, \\ Barcelona, Spain: ${ }^{4}$ Baylor College of Medicine, Houston, TX, USA
}

Submitted 6 July 2007: Accepted 7 September 2007

\begin{abstract}
Aim: The promotion of a healthy and active lifestyle among the population is essential for the prevention of numerous chronic diseases. Physical activity measurement and surveillance is crucial for understanding and evaluating campaigns to promote its practice.

Objective: To evaluate the 10-year trends in physical activity habits in the Catalan population.

Design: Two cross-sectional nutritional surveys were carried out within a 10-year interval in the population of Catalonia. Data on physical activity include leisure-time physical activity, occupational physical activity and walking activity and regular stair climbing.

Subject: In all, 2344 individuals participated in the ENCAT 1992-93 study and 2055 individuals in the ENCAT 2002-03 survey, aged 10 to 75 years.

Results: Inactivity related to occupation increased (from 53\% in 1992-93 to 56\% in 2002-03 of the Catalan population having sedentary work-related activities). In both genders, the percentage of people who walked to work at least 30 min decreased (from $19 \%$ to $16 \%$ in men and from $25 \%$ to $19 \%$ in women). There was a decrease in the percentage of people who were completely sedentary during leisure time (from $59 \%$ to $56 \%$ ), and an increase in the percentage of people who did at least 2 days of vigorous activity (from 39\% to $46 \%$ in men and from $26 \%$ to $32 \%$ in women).

Conclusions: The physical activity related to work and transportation has decreased during the period observed. Although a slight improvement has been noted, the percentage of people who are sedentary during leisure time is still high among both men and women.
\end{abstract}

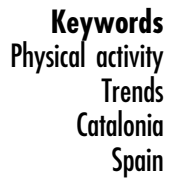

Physical activity has been incorporated as a part of the recommendations for food guides and dietary guidelines in several developed countries ${ }^{1-3}$ due to its relationship to numerous chronic diseases, particularly obesity ${ }^{4}$, coronary heart disease ${ }^{5,6}$, stroke $^{7}$, non-insulin-dependent diabetes ${ }^{8}$, certain types of cancers ${ }^{9}$ and all-cause mortality ${ }^{10,11}$.

Physical activity recommendations have undergone a few modifications in accordance with the outcomes of research related to which aspects of physical activity were related to health, the role of intensity or duration or type of physical activity, and on which aspects of health they influenced (cardiovascular, osteomuscular, metabolism, etc.). The difficulty in measuring habitual physical activity in the population has also added some uncertainties to the resolution of what the recommendations should consist of ${ }^{12}$. Although the debate about the dose-response relationship between physical activity and health is still on-going ${ }^{13,14}$, it appears that physical activity does not have to be of vigorous intensity to yield health benefits for the individual. Public health authorities recommend accumulating at least $30 \mathrm{~min}$ of moderately intense exercise on most days of the week to prevent the appearance of the majority of chronic diseases in the adult population ${ }^{15}$.

Compliance with such recommendations differs between countries. In the USA, data from the Behavioural Risk Factor Surveillance System showed that in 2001, 45\% of adults were active at the reported recommended level ${ }^{16}$. In Europe, the percentage of population that reported to be active during their leisure time varied from $92 \%$ in Finland to $41 \%$ in Portugal ${ }^{17}$. In Spain, available data on physical activity come from different sources: the National Health Survey ${ }^{18}$, a periodical cross-sectional national representative survey and some regional or local surveys. According to data from the National Health 
Survey, in 2003, 34\% of the adult Spanish population had a sedentary job and 58\% of individuals did not realise any exercise during their leisure time. Regional information on physical activity comes from Nutritional Surveys developed in the communities of the Canary Islands ${ }^{19}$, the Basque country ${ }^{20}$, the Balearic Islands ${ }^{21}$, Catalonia ${ }^{22,23}$, Valencia $^{24}$ and Madrid $^{25}$. Local data revealed that in the city of Barcelona ${ }^{26} 19 \%$ of the population did physical activity at least three times a week, $18 \%$ of the adults living in the city of Murcia $^{27}$ did at least $2 \mathrm{~h}$ a week of vigorous physical activity, and $57 \%$ of males and $77 \%$ of females living in the city of Pamplona ${ }^{28}$ were inactive during their leisure time. Information on trends is scarce as it is the information that covers all domains of physical activity such as household, leisure time, transportation or work-related physical activity. Trends data from the National Health Survey showed that the Spanish population has become less inactive during their leisure time (the percentage of the population that did no exercise during leisure time decreased from 63\% in 1987 to 58\% in 2003), but the percentage of people who did exercise regularly (several times per month) showed only a slight increase (9\% in 1993, 11\% in 2001) ${ }^{29}$.

In Catalonia, the Catalan Nutritional Survey ${ }^{22}$ developed in 1992-93 in a representative sample of the population revealed that $59 \%$ of the population were inactive during leisure time, $20 \%$ of the population walked at least $30 \mathrm{~min}$ daily and $48 \%$ of the Catalan population had a sedentary job. The consecutive Health Plans for Catalonia ${ }^{30-34}$ developed periodically since 1991 stated, according to the World Health Organization (WHO) strategy 'Health for All', in the 'Promotion for a positive attitude for health' section, several objectives to improve the level of physical activity of the population through a specific campaign directed to the population. The purpose of the strategy was to improve the knowledge that not only the population but also the health professionals, the primary school teachers and the enterprises had about the relationship between physical activity and health. The 2002-03 Catalan Nutritional Survey included data which permits the analysis of trends of physical activity patterns of the population and compliance with some of the Catalan Health Plan objectives. The same questionnaire for evaluating the physical activity habits was used in the 1992-93 and 2002-03 surveys.

In the present study, the trends (1992-2003) of usual patterns of physical activity in a representative sample of the Catalan population are analysed.

\section{Material and methods}

The Catalan Nutrition Survey is a cross-sectional survey for the study of nutritional status, food habits and physical activity prevalence in a representative sample of the Catalan population. The target population consisted of all inhabitants living in Catalonia, and the sample population was derived from residents registered in the Spanish official population census. Two evaluations have been conducted within a 10-year interval with the same methodology: the ENCAT 1992-9322 survey and the ENCAT 2002-03 ${ }^{23}$ survey.

In ENCAT 1992-93 the theoretical sample was estimated to be 3000 subjects to guarantee a minimum of 100 individuals for each age and sex group. In all, 2757 individuals aged 6-75 years participated in the study (69\% participation) ${ }^{22}$.

In ENCAT 2002-03, the theoretical sample size was set at 3300 individuals, taking into account an anticipated $70 \%$ participation rate, which would result in a sample of approximately 2310 individuals. Finally, 2160 individuals (participation rate 65\%) aged 10 to 80 years participated in the ENCAT 2002-03 study ${ }^{23}$.

The methodology of the study has been described elsewhere $22,23,35$. Information on physical activity was provided by questions adapted from the WHO physical activity CINDI (Countrywide Integrated Noncommunicable Diseases Intervention) questionnaire ${ }^{36}$ used in the ENCAT 1992-93 and ENCAT 2002-03 surveys. Questions about type of physical activity at work, during leisure time and for walking to work (or walking to school or university) and habitual stair climbing were included. Occupational physical activity was classified as sedentary (sitting most of the time), moderate (walking most of the time, no vigorous activities), vigorous (walking most of the time and frequent vigorous activity) or highly active (doing vigorous activities most of the time). Leisure-time physical activity was classified according to its intensity as sedentary (reading, watching TV, etc.), moderate (walking, bicycling, etc.), vigorous (running, skiing, ball games, etc.) and regular physical exercise and training. The frequency of vigorous physical activity for at least 20-30 min was also reported. Vigorous physical activity was defined as that which increases perspiration or makes breathing harder than normal. The questionnaires were administered by trained dietitians and were included in the general questionnaire.

\section{Data analysis}

Data on physical activity at work, during leisure time, way of transport and regular stair climbing in ENCAT 1992-93 and ENCAT 2002-03 were calculated for comparison. The significance of the changes in the prevalences was calculated by $\chi^{2}$ tests. Data were analysed using the statistical package SPSS for Windows version 12.0.

\section{Results}

The final sample for the analysis of physical activity patterns included 2344 individuals (1070 males and 1274 females) in the ENCAT 1992-93 survey and 2055 individuals (952 males and 1103 females) in the ENCAT 2002-03 survey. The subjects' age ranged from 10 to 75 years. 
Table 1 Trends in physical activity pattern in the male Catalan population (1992-2003)

\begin{tabular}{|c|c|c|c|c|c|c|c|c|c|c|c|c|}
\hline \multicolumn{6}{|c|}{ ENCAT 1992-93 } & \multirow[b]{2}{*}{$\begin{array}{c}\text { Age group (years) } \\
n\end{array}$} & \multicolumn{6}{|c|}{ ENCAT 2002-03 } \\
\hline $\begin{array}{c}10-17 \\
150\end{array}$ & $\begin{array}{c}18-24 \\
210\end{array}$ & $\begin{array}{c}25-44 \\
333\end{array}$ & $\begin{array}{c}45-64 \\
278\end{array}$ & $\begin{array}{c}65-75 \\
99\end{array}$ & $\begin{array}{l}\text { Total } \\
1070\end{array}$ & & $\begin{array}{c}10-17 \\
114\end{array}$ & $\begin{array}{c}18-24 \\
125\end{array}$ & $\begin{array}{c}25-44 \\
326\end{array}$ & $\begin{array}{c}45-64 \\
265\end{array}$ & $\begin{array}{c}65-75 \\
122\end{array}$ & $\begin{array}{c}\text { Total } \\
952\end{array}$ \\
\hline \multicolumn{13}{|c|}{ Work-related physical activity } \\
\hline 73.1 & 53.6 & 44.3 & 41.2 & 55.8 & 50.3 & Sedentary (\%) & 71.2 & 56.8 & 41.7 & 48.7 & 69.6 & 52.5 \\
\hline 21.4 & 23.9 & 27.1 & 37.2 & 35.8 & 29.1 & Moderate (\%) & 17.1 & 15.2 & 32.2 & 31.3 & 23.2 & 26.8 \\
\hline 2.1 & 12.4 & 17.8 & 16.4 & 7.4 & 13.3 & Vigorous (\%) & 9.0 & 17.6 & 18.4 & 13.6 & 7.1 & 14.5 \\
\hline 3.4 & 10.0 & 10.8 & 5.1 & 1.1 & 7.3 & Highly vigorous (\%) & 2.7 & 10.4 & 7.7 & 6.4 & 0.0 & 6.2 \\
\hline \multicolumn{13}{|c|}{ Walking to work/study } \\
\hline 15.5 & 34.5 & 47.1 & 52.7 & 56.1 & 42.3 & Do not walk (\%) & 17.1 & 31.2 & 42.9 & 49.8 & 51.8 & 41.3 \\
\hline 60.6 & 41.3 & 39.6 & 30.4 & 19.5 & 38.9 & $<30 \min (\%)$ & 66.7 & 55.2 & 44.4 & 34.2 & 26.3 & 42.5 \\
\hline 17.6 & 17.0 & 9.1 & 9.2 & 11.0 & 12.0 & $30-59 \min (\%)$ & 13.5 & 9.6 & 10.2 & 11.0 & 19.3 & 11.8 \\
\hline 6.3 & 7.3 & 4.2 & 7.7 & 13.4 & 6.8 & $\geq 60 \min (\%)$ & 2.7 & 4.0 & 2.5 & 4.9 & 10.5 & 4.4 \\
\hline \multicolumn{13}{|c|}{ Means of transport } \\
\hline 10.2 & 37.1 & 58.9 & 51.3 & 28.9 & 43.1 & Car (\%) & 18.2 & 40.8 & 64.0 & 56.2 & 31.0 & 49.3 \\
\hline 5.4 & 13.3 & 6.6 & 7.2 & 10.3 & 8.3 & Public transport (\%) & 10.0 & 12.0 & 5.8 & 6.4 & 9.5 & 7.8 \\
\hline 42.2 & 5.7 & 6.3 & 10.1 & 18.6 & 13.3 & Walking/cycling (\%) & 42.7 & 14.4 & 12.9 & 15.8 & 24.1 & 18.8 \\
\hline 21.1 & 22.9 & 12.9 & 18.8 & 32.0 & 19.3 & Walking + public transport (\%) & 20.9 & 20.8 & 9.5 & 15.8 & 29.3 & 16.6 \\
\hline 6.8 & 12.4 & 7.5 & 4.0 & 3.1 & 7.0 & Motorbike (\%) & 4.5 & 8.0 & 6.8 & 3.4 & 0.0 & 4.9 \\
\hline 14.3 & 8.6 & 7.8 & 8.7 & 7.2 & 9.0 & Other (\%) & 3.6 & 4.0 & 0.9 & 2.3 & 6.0 & 2.7 \\
\hline \multicolumn{13}{|c|}{ Stair climbing } \\
\hline 78.7 & 66.3 & 65.6 & 64.8 & 60.0 & 66.8 & Yes (\%) & 80.4 & 72.0 & 69.1 & 68.9 & 47.9 & 68.1 \\
\hline 21.3 & 33.7 & 34.4 & 35.2 & 40.0 & 33.2 & No (\%) & 19.6 & 28.0 & 30.9 & 31.1 & 52.1 & 31.9 \\
\hline \multicolumn{13}{|c|}{ Leisure-time physical activity } \\
\hline 34.0 & 45.0 & 50.0 & 59.6 & 54.5 & 49.7 & Sedentary (\%) & 21.9 & 35.2 & 48.8 & 52.5 & 50.8 & 45.1 \\
\hline 21.3 & 12.0 & 22.0 & 35.7 & 45.5 & 25.7 & Moderate (\%) & 20.2 & 16.8 & 25.5 & 40.0 & 49.2 & 30.8 \\
\hline 32.7 & 30.1 & 21.7 & 4.7 & 0.0 & 18.4 & Vigorous (\%) & 48.2 & 35.2 & 21.8 & 6.4 & 0.0 & 19.6 \\
\hline 12.0 & 12.9 & 6.3 & 0.0 & 0.0 & 6.2 & Sports training (\%) & 9.6 & 12.8 & 4.0 & 1.1 & 0.0 & 4.5 \\
\hline \multicolumn{13}{|c|}{ Vigorous physical activity for at least $20 \mathrm{~min}$} \\
\hline 13.5 & 14.5 & 11.9 & 10.3 & 7.4 & 11.8 & Daily (\%) & 36.0 & 28.0 & 20.4 & 12.9 & 10.0 & 19.9 \\
\hline 50.0 & 40.6 & 25.7 & 13.3 & 4.2 & 26.9 & 2-3/week (\%) & 50.0 & 38.4 & 25.4 & 17.5 & 6.7 & 25.5 \\
\hline 19.6 & 11.1 & 18.0 & 8.9 & 4.2 & 13.3 & 1/week (\%) & 1.8 & 12.8 & 14.6 & 12.9 & 1.7 & 10.7 \\
\hline 9.5 & 15.5 & 13.8 & 8.9 & 1.1 & 11.1 & 2-3/month (\%) & 5.3 & 6.4 & 12.7 & 9.9 & 5.8 & 9.3 \\
\hline 6.8 & 17.9 & 28.4 & 37.3 & 35.8 & 26.2 & Occasionally (\%) & 5.3 & 13.6 & 23.8 & 41.8 & 48.3 & 28.4 \\
\hline 0.7 & 0.5 & 2.1 & 21.4 & 47.4 & 10.7 & Disabled (\%) & 1.8 & 0.8 & 3.1 & 4.9 & 27.5 & 6.2 \\
\hline
\end{tabular}

Tables 1 and 2 show trends for males and females in terms of related activity at work, the time spent walking to work, way of transport and habitual stair climbing, leisure-time physical activity, and the frequency of vigorous physical activity for at least $20 \mathrm{~min}$. An increase in the percentage of persons who have sedentary jobs is observed in all age groups except for younger individuals. The proportion of the population with sedentary work was 50\% in 1992-93 and 53\% in 2002-03 among men and 55\% in 1992-93 and 59\% in 2002-03 among women. There was a significant increase $(P<0.05)$ in the percentage of middle-aged females (45-65 years) that became more sedentary at work (from 38\% to 51\%).

The proportion of males who walked to work/school remained stable, 39\% and 43\% of males in 1992-93 and 2002-03, respectively, walking less than $30 \mathrm{~min}$ a day, with the youngest ones (those in the age group of 10 to 17 years) being the least active. Trends in females showed a significant decrease in the proportion of adolescents and young adults who walked to work/school: in the 1992-93 survey, $50 \%$ of 10-17-year-old females walked less than $30 \mathrm{~min}$, the proportion increased to $61 \%$ in the $2002-03$ survey $(P<0.05)$; for females aged 18-24 years, there was also an increased proportion of those who did not walk to work/school $(P<0.01)$.

The use of the car as the principal means of transport increased in both males and females. In males, the changes were statistically significant for the age groups from 10 to 17 years (increasing from $10 \%$ to $18 \%, P<0.01$ ) and from 25 to 44 years (from $59 \%$ to $64 \%, P<0.01$ ). In females aged 10 to 17 years the use of the car as a means of transport doubled in this time period (from $8 \%$ to $20 \%, P<0.001$ ). Significant increases were also observed in females from 18 to $24(P<0.01)$ years, and from 25 to $44(P<0.001)$ years. Only women aged $65-75$ years increased their walking habits (from 13\% to 38\%, $P<0.05$ ).

Habitual stair climbing increased among the population except for the older group where a decrease was seen (from 60\% to 48\% in 65-75-year-old males).

A slight decrease in the proportion of sedentary leisuretime activities for both males and females was observed (from $50 \%$ to $45 \%$ for males and from $67 \%$ to $63 \%$ for females), being significant in the group aged 45-64 years $(P<0.05$ in males and $P<0.05$ in females). 
Table 2 Trends in physical activity pattern in the female Catalan population (1992-2003)

\begin{tabular}{|c|c|c|c|c|c|c|c|c|c|c|c|c|}
\hline \multicolumn{6}{|c|}{ ENCAT 1992-93 } & \multirow[b]{2}{*}{$\begin{array}{c}\text { Age group (years) } \\
n\end{array}$} & \multicolumn{6}{|c|}{ ENCAT 2002-03 } \\
\hline $\begin{array}{c}10-17 \\
132\end{array}$ & $\begin{array}{c}18-24 \\
265\end{array}$ & $\begin{array}{c}25-44 \\
420\end{array}$ & $\begin{array}{c}45-64 \\
327\end{array}$ & $\begin{array}{c}65-75 \\
130\end{array}$ & $\begin{array}{l}\text { Total } \\
1274\end{array}$ & & $\begin{array}{c}10-17 \\
89\end{array}$ & $\begin{array}{c}18-24 \\
182\end{array}$ & $\begin{array}{c}25-44 \\
376\end{array}$ & $\begin{array}{c}45-64 \\
335\end{array}$ & $\begin{array}{c}65-75 \\
121\end{array}$ & $\begin{array}{l}\text { Total } \\
1103\end{array}$ \\
\hline \multicolumn{13}{|c|}{ Work-related physical activity } \\
\hline 74.6 & 75.5 & 45.3 & 38.3 & 63.5 & 54.7 & Sedentary (\%) & 73.8 & 65.7 & 53.9 & 51.1 & 73.9 & 58.7 \\
\hline 20.8 & 20.3 & 41.9 & 53.6 & 32.5 & 37.2 & Moderate (\%) & 22.6 & 27.6 & 33.0 & 41.6 & 26.1 & 33.1 \\
\hline 4.6 & 4.2 & 12.0 & 7.5 & 4.0 & 7.6 & Vigorous (\%) & 3.6 & 6.6 & 10.7 & 5.8 & 0.0 & 6.8 \\
\hline 0.0 & 0.0 & 0.7 & 0.6 & 0.0 & 0.4 & Highly vigorous (\%) & 0.0 & 0.0 & 2.4 & 1.5 & 0.0 & 1.3 \\
\hline \multicolumn{13}{|c|}{ Walking to work/study } \\
\hline 16.5 & 19.6 & 36.9 & 39.1 & 54.5 & 33.2 & Do not walk (\%) & 18.6 & 29.1 & 37.7 & 45.2 & 61.0 & 39.5 \\
\hline 49.6 & 50.0 & 42.2 & 36.5 & 26.8 & 41.8 & $<30 \min (\%)$ & 60.5 & 51.6 & 47.6 & 33.6 & 18.7 & 41.8 \\
\hline 23.6 & 25.0 & 15.6 & 19.1 & 16.1 & 19.4 & $30-59 \min (\%)$ & 18.6 & 14.3 & 11.2 & 15.2 & 17.8 & 14.2 \\
\hline 10.2 & 5.4 & 5.3 & 5.3 & 2.7 & 5.6 & $\geq 60 \min (\%)$ & 2.3 & 4.9 & 3.5 & 6.1 & 3.4 & 4.4 \\
\hline \multicolumn{13}{|c|}{ Means of transport } \\
\hline 8.3 & 19.2 & 37.8 & 21.8 & 16.5 & 24.6 & Car (\%) & 19.8 & 27.2 & 46.3 & 28.8 & 16.1 & 32.5 \\
\hline 8.3 & 16.5 & 10.6 & 15.1 & 11.8 & 12.9 & Public transport (\%) & 12.8 & 16.7 & 10.4 & 10.0 & 11.9 & 11.7 \\
\hline 32.3 & 7.5 & 10.6 & 17.5 & 13.4 & 14.3 & Walking/cycling (\%) & 39.5 & 16.1 & 15.2 & 22.1 & 38.1 & 21.8 \\
\hline 24.8 & 38.3 & 26.3 & 35.4 & 41.7 & 32.5 & Walking + public transport (\%) & 22.1 & 31.1 & 23.1 & 34.8 & 28.8 & 28.5 \\
\hline 3.0 & 7.5 & 3.1 & 0.9 & 0.0 & 3.2 & Motorbike (\%) & 2.3 & 6.1 & 1.9 & 0.0 & 0.0 & 1.8 \\
\hline 23.3 & 10.9 & 11.6 & 9.2 & 16.5 & 12.6 & Other (\%) & 3.5 & 2.8 & 3.2 & 4.2 & 5.1 & 3.7 \\
\hline \multicolumn{13}{|c|}{ Stair climbing } \\
\hline 76.8 & 63.9 & 65.7 & 66.9 & 64.1 & 66.6 & Yes (\%) & 84.9 & 65.6 & 67.7 & 68.5 & 62.5 & 68.4 \\
\hline 23.2 & 36.1 & 34.3 & 33.1 & 35.9 & 33.4 & No (\%) & 15.1 & 34.4 & 32.3 & 31.5 & 37.5 & 31.6 \\
\hline \multicolumn{13}{|c|}{ Leisure-time physical activity } \\
\hline 55.0 & 63.5 & 63.2 & 73.2 & 84.0 & 67.1 & Sedentary (\%) & 47.2 & 65.9 & 62.0 & 60.6 & 77.7 & 62.7 \\
\hline 16.0 & 14.4 & 25.8 & 21.5 & 14.5 & 20.2 & Moderate (\%) & 22.5 & 11.5 & 24.7 & 35.2 & 20.7 & 25.1 \\
\hline 22.9 & 19.0 & 10.5 & 4.9 & 1.5 & 11.2 & Vigorous (\%) & 25.8 & 20.3 & 12.5 & 4.2 & 0.0 & 11.0 \\
\hline 6.1 & 3.0 & 0.5 & 0.3 & 0.0 & 1.5 & Sports training (\%) & 4.5 & 2.2 & 0.8 & 0.0 & 1.7 & 1.2 \\
\hline \multicolumn{13}{|c|}{ Vigorous physical activity for at least $20 \mathrm{~min}$} \\
\hline 8.7 & 5.1 & 10.4 & 4.8 & 1.6 & 6.8 & Daily (\%) & 21.3 & 13.2 & 12.5 & 8.7 & 5.2 & 11.4 \\
\hline 41.3 & 24.9 & 17.8 & 13.5 & 2.4 & 19.1 & 2-3/week (\%) & 39.3 & 22.5 & 20.0 & 18.3 & 7.0 & 20.1 \\
\hline 31.7 & 15.2 & 9.9 & 5.5 & 3.3 & 11.5 & 1/week (\%) & 14.6 & 7.7 & 9.9 & 6.6 & 7.0 & 8.6 \\
\hline 6.3 & 16.0 & 10.9 & 6.1 & 3.3 & 9.5 & 2-3/month (\%) & 4.5 & 17.6 & 10.1 & 9.9 & 2.6 & 10.0 \\
\hline 10.3 & 37.0 & 47.6 & 49.4 & 33.3 & 40.4 & Occasionally (\%) & 19.1 & 37.4 & 44.3 & 48.5 & 54.8 & 43.5 \\
\hline 1.6 & 1.9 & 3.3 & 20.6 & 56.1 & 12.7 & Disabled (\%) & 1.1 & 1.6 & 3.2 & 8.1 & 23.5 & 6.4 \\
\hline
\end{tabular}

The frequency of vigorous physical activity showed an increase in the daily activity reported in males for almost all age groups: from $14 \%$ to $36 \%$ in $10-17$-year-olds $(P<0.01)$, from $15 \%$ to $28 \%$ in those aged $18-24$ $(P<0.01)$, from $12 \%$ to $20 \%$ in $25-44$-year-olds $(P<0.05)$ and from $10 \%$ to $13 \%$ in $45-64$-year-olds $(P<0.01)$. Referring to females, the oldest group showed an increase in the frequency of vigorous physical activity, both for those aged 45-64 years $(P<0.001)$ and for those aged 65-75 years $(P<0.001)$.

\section{Discussion}

Physical activity questionnaires are one of the most cost-effective methods for assessing physical activity in large-scale population studies. Even when they tend to overestimate the time and intensity of exercise, and to underestimate sedentary behaviours, they are fundamentally useful for assessing patterns, frequency and type of physical activity ${ }^{37}$. In the present analysis, although the responses may have been subject to recall error, measurement error was not differential over time, as the questions were the same in both surveys. As such, the data showed in this report are a valuable tool for evaluating the evolution of physical activity habits in the Catalan population and the effectiveness of the campaigns promoting physical activity among the population.

An overall impression is that the Catalan population has become more sedentary at work and has decreased their habit of walking to work/school. On the other hand, individuals are slightly more active during leisure time. Although cross-country comparisons are difficult because of disparities between methodological aspects including the type of questionnaire used, the results shown are similar to other trend data published. In the USA, the Behavioural Risk Factor Surveillance System presented a decrease in the prevalence of leisure-time physical inactivity (from $30 \%$ to $24 \%$ ) from 1994 to $2004^{38}$. In Canada, leisure-time physical activity data from 1981 to 
2000 showed an increase in the level of activity of adults $^{39}$. In Eastern Finland, a 25-year trend in physical activity showed results similar to the Catalan population, with a reduction of the work-related physical activity, active commuting and an increase in high-intensity leisure-time physical activity ${ }^{40}$. Data from the Minnesota Heart Survey (1980-2000) ${ }^{41}$ showed an increase in daily energy expenditure from lifestyle physical activity and leisure-time physical activity in both genders, and a decrease in workplace activity. In Spain, data on leisuretime physical activity available from the National Health Survey (1993-97) revealed that there was a decrease in the proportion of the Spanish population that was completely sedentary during their leisure time (from 55\% to $46 \%)^{28}$. On the other hand, the data from our study contrasted with that from England ${ }^{42}$, Sweden ${ }^{43}$ or Australia $^{44}$, where there was a decrease in the level of leisure-time activity practice of the population.

The questions related to work (type of activity and walking habits to work) included individuals from 65 to 75 years. As most of them are retired, the results have to be analysed with caution. Their reported work-related physical activity might be, in some cases, the physical activity related to non-paid work or leisure-time activities or volunteer related activities, etc.

The magnitude of changes in leisure-time physical activity is assessed by the number of days dedicated to carrying out vigorous physical activities for at least 20 min. Observed trends showed that both males and females increased their frequency of practice. Had the magnitude of such an increase represented greater net daily energy expenditure, the tendency would have been encouraging. However, to date and as reported in Finland, the observed increases of leisure-time energy expenditure do not counterbalance the declines seen in the energy demands of work activity ${ }^{45}$, and as such this represents a decrease in total energy expenditure over time. In ENCAT 2002-03, 39\% of the Catalan population ( $45 \%$ of males and $32 \%$ of females) reported conducting at least 2 days of vigorous physical activity for a minimum of $20 \mathrm{~min}$. It has been previously reported that women tend to be less involved in vigorous-intensity physical activity than men, although it has also been observed that women are as active as men when all domains of physical activity are taken into account ${ }^{37}$. Any questionnaire that limits the study of physical activity patterns to leisure-time physical activity will underreport the values for women, as they tend to spend more time on household and family-care tasks, which implies a greater magnitude of moderate-intensity activities. On the other hand, recall and measurement error are greater for light- and moderateintensity activity than for vigorous activity ${ }^{46}$. Although the description of the intensity of exercise may help to classify the effort realised by an individual, perceived effort is a personal sensation and older individuals may feel that the exercise they are doing is of more intensity than it really is. The observed increase in the number of women older than 45 years who exercise vigorously may be explained by the increase in the proportion of women of that age group who have changed their sedentary habits and have become active, independent of the intensity of the activity realised.

Nevertheless, the proportion of the Catalan population that has sedentary habits is still high ( $55 \%$ of the population, in the ENCAT 2002-03 analysis), and especially regarding females (63\% of them having sedentary habits). The Catalan Health Plan published in $1991^{30}$ stated the intention to reduce to $40 \%$ the proportion of Catalan individuals with sedentary habits by the year 2000, an objective which was not achieved in 2002-03. Most of the recommendations directed to the general population refer to increasing moderately intense physical activity, and emphasising the necessity to accumulate $30 \mathrm{~min}$ or more of moderately intense activity on most days of the week $^{38}$ to achieve improvements on health status. Walking is an activity that can be easily incorporated and maintained in day-to-day life so as to achieve these recommendations. Another of the objectives of the Catalonia Health Plan for the year 2000 was to improve by $50 \%$ the proportion of people who walk at least $30 \mathrm{~min}$ a day. Unfortunately, the Catalan population does not seem to follow this guideline. The number of people who walk to work/school $30 \mathrm{~min}$ or more per day has decreased in a decade and $66 \%$ of the population do not walk or walk less than $15 \mathrm{~min}$ daily to go to work. An in-depth evaluation of the all-purpose walking habits of the population may have increased the proportion of people who comply with the daily recommendations. But data from the Catalan Health Survey ${ }^{47}$, a periodically developed survey to evaluate health status of the population of Catalonia since 1989, included some questions on physical activity that did not confirm this supposition. In $1989,61 \%$ of the adult Catalan population walked at least $30 \mathrm{~min}$ daily, the proportion increased up to $77 \%$ in $1992-93$ and decreased again to $61 \%$ in the 2002-03 survey $^{47}$.

It is of utmost importance to address the promotion of physical activity among the population. Until now, the campaigns to decrease sedentary habits among the population in Catalonia had focused mostly on individuals instead of on the community. Lately, much effort has been put into increasing the environmental possibilities to facilitate the opportunities to walk, bike and use public transport among the population (increasing the availability of bike and walking lanes in the big cities). Similar increased opportunities to walk or exercise should be made at the workplace as well. The literature provides evidence that multidisciplinary action involving the family, the environment, the school, etc. are the most efficient to increase the physical activity habits of a population ${ }^{48}$. Special input should be made at the workplace. It is time to act on these fronts to face the epidemics of inactivity. 
Otherwise, it will be of great difficulty to reverse the trend of increasing overweight and obesity prevalence in the Spanish and Catalan population.

\section{Acknowledgements}

Sources of funding: This work was made possible by financing from the General Division of Public Health of the Generalitat of Catalonia's Department of Health, through a research agreement with the Fundación para la Investigación Nutricional (Nutrition Research Foundation).

Conflict of interest declaration: None of the authors had any conflicts of interest in connection with this study.

Authorship responsibilities: BRV was responsible for the interpretation of physical activity data and the writing of the paper, LSM was director of the study and revised the paper providing expert advice on data interpretation and discussion of the paper, LRB was responsible for the statistical analysis and revised the paper providing expert advice on data interpretation, ERC, CC, CV and AP provided expert advice on data interpretation and in the discussion of the paper.

Guarantor: Lluís Serra-Majem.

Acknowledgements: Special acknowledgement is made to all those persons who were interviewed, and whose collaboration made the realisation of these surveys possible.

Research Group on the Evaluation and Monitoring of the Nutritional Status in the Catalan Population: Lluís Serra-Majem, Director (University of Las Palmas de Gran Canaria); Lourdes Ribas-Barba, Coordinator (FIN Nutrition Research Foundation, Barcelona Science Park); Gemma Salvador (Generalitat of Catalonia); Conxa Castell (Generalitat of Catalonia); Blanca Román - Viñas (FIN, Barcelona Science Park); Jaume Serra (Generalitat of Catalonia); Lluís Jover (University of Barcelona); Ricard Tresserras (Generalitat of Catalonia); Blanca Raidó (FIN, Barcelona Science Park); Andreu Farran (CESNID, University of Barcelona); Joy Ngo (FIN, Barcelona Science Park); Mari Cruz Pastor (Hospital Germans Trias i Pujol, Badalona); Lluís Salleras (University of Barcelona); and Carmen Cabezas, Josep Lluís Taberner, Salvi Juncà, Josep Maria Aragay, Eulàlia Roure, Gonçal Lloveras Vallès $(†$ 2003), Antoni Plasencia (Generalitat of Catalonia).

\section{References}

1 Brooks GA, Butte NF, Rand WM, Flatt JP, Caballero B. Chronicle of the Institute of Medicine physical activity recommendation: How physical activity recommendation came to be among dietary recommendations. American Journal of Clinical Nutrition 2004; 79(Suppl.): 921S-30S.

2 Serra Majem LL, Aranceta J, SENC Working Group on Nutritional Objectives for the Spanish Population. Spanish
Society of Community Nutrition. Public Health Nutrition 2003; 6: 333-4.

3 U.S. Department of Health and Human Services and U.S. Department of Agriculture. Dietary Guidelines for Americans 2005. Sixth editions. Washington, DC: US Government Printing Office, 2005.

4 Hill JO, Wyatt HR. Role of physical activity in preventing and treating obesity. Journal of Applied Physiology 2005; 99: 765-70.

5 Kohl III HW. Physical activity and cardiovascular disease: evidence for a dose response. Medicine and Science in Sports and Exercise 2001; 33: S472-83.

6 Sundquist K, Qvist J, Johansson SE, Sundquist J. The longterm effect of physical activity on incidence of coronary heart disease: a 12-year follow-up study. Preventive Medicine 2005; 41: 219-25.

7 Lee IM, Paffenbarger RS. Physical activity and stroke incidence: the Harvard Alumni Health Study. Stroke 1998; 29: 2049-54.

8 Hu FB, Manson JE, Stampfer MJ, Colditz G, Liu S, Solomon CG, et al. Diet, lifestyle, and the risk of type 2 diabetes mellitus in women. New England Journal of Medicine 2001; 345: 790-7.

9 Lee IM. Physical activity and cancer prevention - data from epidemiologic studies. Medicine and Science in Sports and Exercise 2003; 35: 1823-7.

10 Hu G, Tuomilehto J, Silventoinen K, Barengo NC, Peltonen M, Jousilahti P. The effects of physical activity and body mass index on cardiovascular, cancer and all-cause mortality among 47,212 middle-aged Finnish men and women. International Journal of Obesity 2005; 29: 894-902.

11 Blair SN, Brodney S. Effects of physical inactivity and obesity on morbidity and mortality: current evidence and research issues. Medicine and Science in Sports and Exercise 1999; 31(Suppl.): S646-62.

12 LaPorte RE, Montoye HJ, Caspersen CJ. Assessment of physical activity in epidemiologic research: problems and prospects. Public Health Reports 1985; 100: 131-46.

13 Kesaniemi YK, Danforth Jr E, Jensen MD, Kopelman PG, Lefebvre P, Reeder BA. Dose-response issues concerning physical activity and health: an evidence-based symposium. Medicine and Science in Sports and Exercise 2001; 33(Suppl.): S351-8.

14 Blair SN, Cheng Y, Holder JS. Is physical activity or physical fitness more important in defining health benefits? Medicine and Science in Sports and Exercise 2001; 33(Suppl.): S379-99.

15 US Department of Health and Human Services. Physical activity and health: a report of the Surgeon General. Atlanta, GA: US Department of Health and Human Services, Centres for Disease Control and Prevention, National Centres for Chronic Disease Prevention and Health Promotion, 1996; 146-8.

16 Macera CA, Ham SA, Yore MM, Jones DA, Ainsworth BE, Kimsey CD, et al. Prevalence of physical activity in the United States: Behavioral Risk Factor Surveillance System, 2001. Preventive Chronic Disease 2005; 2: A17. Available at http://www.cdc.gov/pcd/issues/2005/apr/04_0114.htm. Accessed 15 December 2006.

17 Martínez-González MA, Varo JJ, Santos JL, De Irala J, Gibney $\mathrm{M}$, Kearney J, et al. Prevalence of physical activity during leisure time in the European Union. Medicine and Science in Sports and Exercise 2001; 33: 1142-6.

18 Ministerio de Sanidad y Consumo. Información y estadísticas sanitarias. Epidemiología. Promoción y Educación para la salud. Salúd Pública. Encuesta Nacional de Salud de España. Madrid: Ministerio de Sanidad y Consumo, 1997.

19 Serra Majem L, Cabrera Leon A, Sierra Lopez A. Conclusions of the Canary Islands Nutrition Survey (1997-98). Foundations for a nutrition policy in Canary Islands. Archivos Latinoamericanos de Nutricion 2000; 50(Suppl. 1): 62-70. 
20 Aranceta J, Pérez-Rodrigo C, Marzana I, Eguileor I, González de Galdeano L, Sáenz de Buruaga J. Encuesta de nutrición de la Comunidad Autónoma Vasca. Tendencias de consumo alimentario, indicadores bioquímicos y estado nutricional de la población adulta. Vitoria: Servicio de Publicaciones Gobierno Vasco, 1995.

21 Tur Marí JA, Obrador Adrover A, edsLibro Blanco de la Alimentación y la Nutrición en las Islas Baleares. Estudio de nutrición de las Islas Baleares ENIB (1999-2000). Revista de Ciencia 2002; 27: 1-18.

22 Serra Majem L, Ribas Barba L, García Closas R, Ramon JM, Salvador G, Farran A, et al. Llibre Blanc: Avaluació de l'estat nutricional de la població catalana (1992-93). Barcelona: Departament de Sanitat i Seguretat Social, Generalitat de Catalunya, 1996.

23 Serra Majem L, Ribas Barba L, Salvador Castell G, Castells Abat C, Román Viñas B, Serra J, et al. Avaluació de l'estat nutricional de la població catalana 2002-2003. Evolució dels hàbits alimentaris $i$ del consum d'aliments $i$ nutrients a Catalunya (1992-2003). Barcelona: Departament de Salut, Generalitat de Catalunya, 2006.

24 Vioque J, Quiles J. Encuesta de Nutricion y Salud de la Comunidad Valenciana. Alicante: Departamento de Salud Pública, 2003.

25 Aranceta J, Pérez Rodrigo C, Amela C, García Herrera R. Encuesta de nutrición de la Comunidad de Madrid. Madrid: Consejería de Salud de la Comunidad de Madrid, 1994.

26 Dominguez-Berjon MF, Borrell C, Nebot M, Plasencia A. Leisure time physical activity and its association with demographic variables and other behaviors related with health. Gaceta Sanitaria 1998; 12(3): 100-9.

27 Martínez-Ros MT, Tormo MJ, Perez-Flores D, Navarro C. Physical sports activity in a representative sample of the population of Region de Murcia, Spain. Gaceta Sanitaria 2003; 17(1): 11-19.

28 Elizondo-Armendariz JJ, Guillen Grima F, Aguinaga Ontoso I. Prevalence of physical activity and its relationship to sociodemographic variables and lifestyles in the age 18-65 population of Pamplona, Spain. Revista Española de Salud Publica 2005; 79(5): 559-67.

29 Moreno LA, Sarría A, Popkin BM. The nutrition transition in Spain: a European Mediterranean country. European Journal of Clinical Nutrition 2002; 56: 992-1003.

30 Generalitat de Catalunya, Departament de Sanitat i Seguretat Social. Document marc per a la elaboració del Pla de Salut de Catalunya. Barcelona: Departament de Sanitat i Seguretat Social, 1991.

31 Generalitat de Catalunya, Departament de Sanitat i Seguretat Social. Pla de Salut de Catalunya 1993-1995. Barcelona: Departament de Sanitat i Seguretat Social, 1993.

32 Generalitat de Catalunya, Departament de Sanitat i Seguretat Social. Pla de Salut de Catalunya 1996-1998. Barcelona: Departament de Sanitat i Seguretat Social, 1996.

33 Generalitat de Catalunya, Departament de Sanitat i Seguretat Social. Pla de Salut de Catalunya 1999-2001. Barcelona: Departament de Sanitat i Seguretat Social, 1999.
34 Generalitat de Catalunya, Departament de Sanitat i Seguretat Social. Pla de Salut de Catalunya 2002-2005. Barcelona: Departament de Sanitat i Seguretat Social, 2002.

35 Ribas-Barba L, Serra-Majem L, Salvador G, Castell C, Cabezas C, Salleras L, Plasencia A. Trends in dietary habits and food consumption in Catalonia, Spain (1992-2003). Public Health Nutrition 2007; 10(11A): 1340-53.

36 Countrywide Integrated Noncommunicable Diseases Intervention (CINDI) Programme. Protocol and guidelines. Copenhagen: WHO Regional Office for Europe, 1991.

37 Livingstone MBE, Robson PJ, Wallace JMW, McKinley MC. How active are we? Levels of routine physical activity in children and adults. Proceedings of the Nutrition Society 2003; 62: 681-701.

38 Centers for Disease Control and Prevention (CDC). Trends in leisure-time physical inactivity by age, sex, and race/ ethnicity-United States, 1994-2004. Morbidity and Mortality Weekly Report 2005; 54: 991-4.

39 Craig CL, Russell SJ, Cameron C, Bauman A. Twenty-year trends in physical activity among Canadian adults. Canadian Journal of Public Health 2004; 95: 59-63.

40 Barengo NC, Nissinen A, Tuomilehto J, Pekkarinen H. Twenty-five-years trends in physical activity of 30 to 59 year old populations in eastern Finland. Medicine and Science in Sports and Exercise 2002; 34: 1302-7.

41 Steffen LM, Arnett DK, Blackburn H, Shah G, Armstrong C, Luepker RV, et al. Population trends in leisure-time physical activity: Minnesota Heart Survey, 1980-2000. Medicine and Science in Sports and Exercise 2006; 38: 1716-23.

42 Prior G. Physical activity. In: Erens B, Primatesta P, eds. Health Survey for England: Cardiovascular Disease vol. 1. The Stationary Office, 1999 .

43 Lindström M, Isacsson SO, Merlo J. Increasing prevalence of overweight, obesity and physical inactivity. Two population-based studies 1986 and 1994. European Journal of Public Health 2003; 13: 306-12.

44 Bauman A, Armstrong T, Davies J, Owen N, Brown W, Bellew B, et al. Trends in physical activity participation and the impact of integrated campaigns among Australian adults, 1997-1999. Australian and New Zealand Journal of Public Health 2003; 27: 76-9.

45 Fogelholm M, Mannisto S, Vartiainen E, Pietinen P. Determinants of energy balance and overweight in Finland 1982 and 1992. International Journal of Obesity and Related Metabolic Disorders 1996; 20: 1097-104.

46 Shephard RJ. Limits to the measurement of habitual physical activity by questionnaires. British Journal of Sports Medicine 2003; 37: 197-206.

47 Roure E, Vallbona C, Tresserras R, Taberner JL, Salleras L. Physical activity. Evaluation of the objectives of the Health Plan for Catalonia for the year 2000. Medicina Clinica (Barc) 2003; 121(Suppl. 1): 51-5.

48 Kahn EB, Ramsey LT, Brownson RC, Heath GW, Howze EH, Powell KE, et al. The effectiveness of interventions to increase physical activity. A systematic review. American Journal of Preventive Medicine 2002; 22(4S): 73-107. 